it seems to do for Paramecium ${ }^{4,5}$; this term is further of value as part of a relatively homogeneous classification of elementary reactions ${ }^{3,6}$. It is worth while noticing that sensory adaptation is an essential feature of successful aggregation in the eccritic part of a smooth gradient, when a random turning mechanism is used ${ }^{2,6}$, while it is apparently not so important at a boundary.

Mr. Yapp's conclusion would be justified, therefore, only if smooth gradients .were merely "unusual experimental conditions" and sharp boundaries were the natural conditions in which "ordinary behaviour" occurred. I should have thought that in the habitat of Paramecium and on the microscopic scale involved, smooth gradients would be the rule and sharp boundaries the exception.

I agree that there need be no teleological assumption in using the term avoiding reaction ${ }^{6}$; but I suppose Mr. Yapp would agree that it would be a pity to use the term unless one could be sure that no teleological implication would be read into it.

Department of Zoology,

University of Birmingham. Dec. 26.

1 Yapp, NATURe, 148, 754 (1941).

- Ullyott, J. Exp. Binl., 13, 265 (1936).

- Gunn, Kennedy and Pielou, NatUre, 140, 1064 (1937).

"Yapp, "Introduction to Animal Physiology" (Oxford, 1939).

- Gunn and Walshe, NATURe, 148, 564 (1941).

"Fraenkel and Gunn, "The Orientation of Animals" (Oxford, 1940).

\section{Rapid Determination of Water in Animals and Plants}

DR. L. G. G. WARNE ${ }^{1}$ is, of course, correct in maintaining that toluene with its boiling-point of $110 \cdot 7^{\circ} \mathrm{C}$. is preferable to xylol (b.p. about $135^{\circ} \mathrm{C}$.) in the method recently described by $\mathrm{me}^{2}$. Unfortunately in the work which is going on at Plymouth one has to deal with large quantities of water and it is much easier to obtain xylol at the present time than it is to obtain toluene. I would like, however, to point out that the determination of water is only a comparatively small part of the work.

A method was devised in $1938^{3}$ by which it is possible to weigh accurately such organisms as prawns, sponges, fishes or aquatic larvæ or embryos without removing them from the water, and this has opened up a vast field for research, for having weighed the fish or sponge one can then begin to carry out a quantitative analysis. Surely it will be recognized by all that this must have a great advantage over the older method of first, more or less, drying the organism or tissue and then carrying out the analysis.

Since 1938 the technique has been greatly improved and it is possible to weigh the organisms with much greater accuracy; but, of course, it is not possible to weigh a living sponge or shrimp with the same accuracy that one can weigh a crystal of quartz or calcite, and even if one could do so the figure would be meaningless, for the weight of a living organism must alter from minute to minute if not from second to second.

The displacement method of weighing has been fully described and discussed and I trust that a full account will shortly occur in the Journal of the Marine Biological Association.

The method of determining the water in organisms as recently described may be of great interest in another direction, for it is well known that drying an organism either in vacuo or in the oven even at a temperature at which most of the tissues would be charred or largely decomposed does not remove the bound water which is of such interest in biochemistry. It is quite conceivable, however, that even the bound water is removed by distilling the tissue under xylol or toluene.

Whether I was or was not the first to apply the Dean and Stark's tube for ascertaining the percentage of water in a sponge or prawn is a matter of no concern to me, and my sole reason for publishing a short account of the method was that I was urged to do so by Dr. Joseph Needham after he had seen a Soxhlet extraction apparatus used as a Dean and Stark's tube as described in my recent communication. It appears, therefore, that the method is not too well known in biochemistry.

The Laboratory,

A. G. Lowndes.

Citadel Hill,

Plymouth.

Dec. 21.

1.Warne, L. G. G., NATURE, 148, 756 (1941).

2 Lowndes, A. G., NATURe, 148, 594 (1941).

${ }^{3}$ Lowndes, A. G., Nature, 141, 289 (1938).

\section{Scientific Help for the Home Guard}

May I through the columns of Nature ask the technical help of readers for the Home Guard ?

Although excellent equipment is now available to the Home Guard of an orthodox nature through the official channels, it still remains possible to supplement this by private ingenuity. I am inaugurating at this School a course in unorthodox weapons, gadgets and booby traps, and I would value information and suggestions from readers who have technical knowledge about how to make any of the following :

(a) Alarms to be attached to trip wires, etc.

(b) Detonators and electric circuits enabling mines, etc., to be exploded from some distance.

(c) Booby traps, electrically and otherwise controlled.

(d) Smoke bombs and methods of producing smoke screens.

(e) Home-made explosives.

(f) Home-made inflammable materials, such as the well-known phosphorus bombs.

(g) Home-made periscopes and other optical instruments.

(h) Simple signalling apparatus, buzzers, etc.

(i) Bird calls and other decoy noises.

In short, anything the physical or chemical properties of which can be usefully turned by the amateur to the successful harrying of the enemy. It is, of course, essential that these tools can be made by the amateur out of odd scraps of material likely to be found ready to hand. Certain of the things in the above list are for the moment prohibited, but this does not mean that it will not be worth while having at least the recipes by us in case the ban is lifted, either legally or by circumstance.

JoHN Langdon-Davies.

Home Guard Fielderaft School, (Capt. Commandant.)

Bowmans, Burwash,

Sussex.

Dec. 30 . 